\title{
The insider: A planners' perspective on accessibility
}

For Citation Please use: Boisjoly, G., \& El-Geneidy, A. (2017). The insider: A planners' perspective on accessibility. Transport Geography, 64, 33-43.

\begin{abstract}
Accessibility, the ease of reaching destinations, is a key land use and transportation performance measure that has been studied for decades by researchers. Nevertheless, its use by practitioners is generally limited. The goal of this study is to explore the challenges and opportunities experienced by land use and transportation practitioners to use accessibility metrics in their work. In order to achieve this objective, a survey on the use of accessibility metrics was conducted among 343 practitioners around the world. Findings from the survey show a gap between knowledge of the concept of accessibility and its use by land use and transportation practitioners. While $90 \%$ of the respondents are familiar with the concept, only 55\% stated that they use accessibility metrics in their work. Whereas lack of support and interest does not appear to be a major obstacle to using accessibility metrics, lack of knowledge and data are highlighted as the main barriers to the use of metrics in practice. These results suggest that further training and collaboration is required to support the use of metrics by practitioners. Furthermore, including clear accessibility indicators in planning documents is key to promoting the use of metrics in policy and practice, as it was stated as a main reason motivating the generation of accessibility metrics. This research highlights potential avenues to support the integration of accessibility metrics in practice and is of relevance to researchers, planners and policy-makers wishing to foster accessibility-based planning approaches.
\end{abstract}

Key words: Accessibility metrics, Accessibility planning, Sustainable mobility, Access to destinations, Land use and transportation planning 


\section{INTRODUCTION}

Accessibility, the ease of reaching destinations, is a key land use and transportation performance measure (Wachs and Kumagai, 1973). It is increasingly used by researchers to spatially assess the joint benefits provided by the transportation network and the land use system in a region (Huang and Wei, 2002; Kawabata and Shen, 2007; Bocarejo and Oviedo, 2012; Manaugh and El-Geneidy, 2012) and to identify spatial gaps in access to opportunities (Paez et al., 2010b, a). Understanding and visualizing accessibility patterns and changes across a region contributes to developing spatially targeted land use and transportation interventions. While accessibility has been extensively researched with the ultimate purpose of informing decisionmaking and influencing land use and transportation planning, little is known on the use of accessibility metrics in transportation practice. In fact, although transportation issues are increasingly framed in terms of access to opportunities (Preston and Rajé, 2007; Handy, 2008; Geurs et al., 2012; Lucas, 2012; Manaugh et al., 2015), accessibility is still largely marginalized in practice (Levinson and Gillen, 2005; Halden, 2011; Proffitt et al., 2015). More specifically, accessibility goals are increasingly incorporated in transportation plans, but the use of performance indicators reflecting the ease of reaching destinations is limited (Handy, 2008; Proffitt et al., 2015; Boisjoly and El-Geneidy, 2017).

The aim of this study is, therefore, to explore the challenges and opportunities experienced by a variety of land use and transportation practitioners with respect to the use of accessibility metrics in their work. This study assesses the familiarity with and use of the concept and metrics as well as the motivations and barriers to using accessibility metrics among 343 practitioners from around the world, mainly North America and to a lesser extent Europe. In order to achieve the study aim, a survey on the use of accessibility metrics was conducted among land use and transportation practitioners through an on-line platform. This study contributes to a greater understanding of the practical challenges related to the use of accessibility metrics by practitioners. Understanding such challenges is essential to bring accessibility indicators into practice, and accordingly provide planners and decision-makers with performance indicators to spatially assess the benefits provided by land use and transportation improvements. This study is of relevance to researchers, planners and policy-makers wishing to foster accessibility-based planning approaches. 


\section{LITERATURE REVIEW}

Accessibility, defined as the ease of reaching destinations (Preston and Rajé, 2007), is one of the most comprehensive performance measures of land use and transportation systems (El-Geneidy and Levinson, 2006). As such, accessibility reflects the multiple benefits provided by land use and transportation systems (Ben-Akiva and Lerman, 1979). For example, greater accessibility is associated with higher land values (Koenig, 1980; El-Geneidy and Levinson, 2006; Du and Mulley, 2012) and employment rates (Ornati et al., 1969; Pignatar and Falcocch, 1969; Sanchez, 1999; Blumenberg and Ong, 2001; Sari, 2015; Tyndall, 2015), as it provides residents with greater access to a variety of opportunities. In the same way, increased accessibility contributes to reducing the risks of social exclusion for vulnerable individuals (Preston and Rajé, 2007; Lucas, 2012). Furthermore, accessibility by transit is associated with greater transit use (Chen et al., 2008; Owen and Levinson, 2015b), and can thus help in reducing car use and the resulting greenhouse gas emissions (Levinson, 1998; Handy, 2002). Accessibility improvements can also have negative impacts on individuals. For example, increased accessibility can lead to neighborhood gentrification, as it is often associated with increase in land values, and adversely affect lowincome residents. Furthermore, congestion is often associated with areas with high levels of accessibility (Mondschein et al., 2011). Nonetheless, as accessibility comprehensively reflects the outcomes of land use and transportation systems, it is increasingly put forward as a key element of a transportation planning (Handy, 2002; Banister, 2008; Straatemeier, 2008).

Accessibility is contingent on a variety of interacting factors. Firstly, access to destinations is largely influenced by the distribution of residential, economic, cultural and social activities (the land use component). Accessibility further depends on the transportation network which determines the travel time, costs and convenience from a place (for example, home) to another (for example, work) (the transport component). In addition to the exogenous factors, individual characteristics such as income, level of education, gender and vehicle ownership affect one's abilities and needs to access destinations (the individual component). Time restrictions also play an important role in determining accessibility. These include land use, transport and individual constraints such as the availability of opportunities (i.e., opening hours), personal schedules, and the schedule of public transport services.

Given the wide scope of factors affecting accessibility, multiple and diverse accessibility metrics have been developed (Handy and Niemeier, 1997; Geurs and van Wee, 2004; Miller, 2005; 
Paez et al., 2012), differing in their level of disaggregation and their ease of operationalization. Person-based measures of accessibility are generated at the individual level, and are concerned with the level of accessibility experienced by a specific person (Geurs and van Wee, 2004; Miller, 2005; Owen and Levinson, 2015b). These measures incorporate the characteristics of the land use and transportation systems, as well as the spatial and temporal constraint of the individual into a single measure (Miller, 2005). Person-based measures are helpful in understanding individual experiences of accessibility, but entail significant challenges to assess land use and transportation systems at a regional scale. A second type of measures are the utility-based measures, which capture the economic benefits provided by changes in the network. Utility-based measures account for most components of accessibility and can be included in traditional cost-benefit analysis (van Wee, 2016). Yet, these measures are rarely used in practice due to the challenges related to their interpretability and communicability (van Wee and Geurs, 2016).

In contrast, location-based metrics are most commonly used in planning as they provide a comprehensive measure of regional accessibility (Boisjoly and El-Geneidy, 2017). These metrics indicate the ease of accessing destinations from a specific location and accounts for the spatial distribution of opportunities (for example, jobs or healthcare services) and the ability to move from one place to another (Geurs and van Wee, 2004). The transport component, the ability to move from one place to the other, is generally mode specific and based on travel time or distance (Hansen, 1959; Vickerman, 1974; Handy, 1994; Geurs and van Wee, 2004; Owen and Levinson, 2015a). A common location-based metric is a measure of cumulative-opportunities, which counts all opportunities that can be reached within a travel costs threshold. For example, the number of jobs that are within 45 minutes of travel times by transit from a specific place is used to assess the access to jobs by public transit. Another common metric is the gravity-based measure, which discounts opportunities based on a distance-decay function. Accordingly, opportunities that are located farther (by distance or time) receive less weight than closer opportunities. While this measure is more reflective of travel behavior, cumulative-opportunities are simpler to generate, interpret and communicate.

Although accessibility has been extensively researched, its inclusion in transportation planning is limited; the mobility-based approach still dominates transportation planning (Levinson and Gillen, 2005; Halden, 2011; Proffitt et al., 2015). This approach, which traditionally focused on motorized traffic, aims at facilitating the smooth movement of vehicles. In this regard, the goal 
is to minimize travel times by increasing travel speeds and reducing travel delays. Within this approach, interventions are generally develop to meet the demand through improvements on the network, while neglecting the land use components that can contribute to improving access to destinations. This approach is widely used for car traffic, but also for public transport and cycling. Through a detailed assessment of four transportation plans in California, Handy (2005) found that although accessibility emerged as a concern in most plans, these plans were still dominated by a mobility-oriented paradigm. Similarly, in an assessment of 42 American transportation plans, Proffitt et al. (2015) found that less than a quarter of the plans measured success based on accessibility indicators. In the United Kingdom (UK), the national government has established a framework for accessibility planning. However, the broad and flexible guidelines resulted in a "misuse" and "abuse in practice" of accessibility (Halden, 2011). Research has also shown that there is a lack of consensus on the accessibility indicators to be used in transportation evaluations (Halden, 2011; van Wee, 2016).

Increasing interest is given to accessibility metrics as a tool to better integrate land use and transportation planning and to address issues of geographic access to opportunities. While many studies have focused on accessibility metrics and indicators, no study has, to our knowledge, looked into the use of accessibility metrics by practitioners. Yet, understanding how and to what extent accessibility indicators are used in practice is essential to bridge the gap between planning and research, and to foster the implementation of accessibility-oriented planning approaches.

\section{DATA AND METHODOLOGY}

To explore the factors influencing the use of accessibility metrics in practice, a survey was conducted among land use and transportation practitioners. The survey was conducted on-line, and disseminated through various mailing lists and social media groups of planners. The main goal was to identify practitioners that use accessibility in their work and determine the motivations and barriers behind generating accessibility metrics. Since this study is mainly concerned with the use of accessibility metrics in land use and transportation planning, the survey focused on locationbased metrics. As discussed above, these metrics address the characteristics of the land use and transport systems at a regional level and are most commonly used in the planning realm given their ease of interpretation and communication. 
The selection and subdivision of respondents included in this study are presented in FIGURE 1. In total, 440 fully completed surveys were collected. As the objective was to focus on land use and transportation planning practice, only land use and transportation practitioners were included in the sample. The term land use and transportation practitioners is broadly used to refer to any individual involved with land use and/or transportation planning and does not include individuals mainly concerned with research activities. Respondents were, therefore, included or excluded based on their sector of employment, company/organization and job title. Firstly, any respondent who selected academia as their sector of employment (70 respondents) was excluded from the sample. Secondly, respondents who indicated educational or research institution as their organization were also excluded (9 respondents). Finally, architects working in an architecture firm were also excluded from the original sample (3). Overall, in this study, land use and transportation practitioners are mainly planners, managers, analyst or engineers working in the public, private or non-governmental sector, and all of them are involved with transportation and/or land use projects.

Furthermore, all respondents were asked about their familiarity and use of the concept and metrics (see detailed questions in FIGURE 1, right). Respondents that were neither familiar with the concept nor the metrics were removed (15 respondents). In total, 343 nonacademic respondents were included in the final sample, of which 274 were from North America, 45 from Europe, and 24 from other regions. These respondents were then divided in three subsamples, based on whether they used the concept and metrics of accessibility in their work. Respondents that "neither agreed nor disagreed", "agreed" or "strongly agreed" with the statement "I use the CONCEPT of accessibility in my work" were considered as using the concept. Similarly, respondents that "neither agreed nor disagreed", "agreed" or "strongly agreed" with the statement "I use accessibility METRICS in my work" were considered as using the metrics. The three subsamples are as follows:

A. Respondents that used accessibility metrics in their work (Metrics; N=247).

B. Respondents that did not use accessibility metrics in their work, but that did use the concept of accessibility (Concept; $\mathrm{N}=68$ ).

C. Respondents that did not use the concept of accessibility, nor the metrics, in their work (Others; $\mathrm{N}=28$ ).

The survey was divided in 4 sections. The first section included general questions about the respondents' work context. The second section asked respondents about their familiarity with and use of the concept and metrics, to divide the respondents into subsamples. The third section 
asked respondents $\mathrm{A}$ and $\mathrm{B}$ about their use of the metrics and concept respectively. The first subsample (respondents that used metrics) was asked specific questions about the design and use of metrics, whereas the second subsample (respondents using the concept, but not the metrics) was asked specific questions about their use of the concept, and reasons for not using metrics. The fourth section questioned all respondents about their perception on the use of accessibility metrics in decision-making. Throughout the survey, agreement questions used a 5-point Likert scale (1"strongly disagree", 2-“disagree", 3-“neither agree nor disagree", 4-“agree”, 5-“strongly agree"). In the analysis of the results, respondents that selected "agree" and "strongly agree" were aggregated together as "agree", and respondents that selected "disagree" and "strongly disagree" were aggregated together as "disagree". Respondents who selected "neither agree nor disagree" were considered as "neutral". 


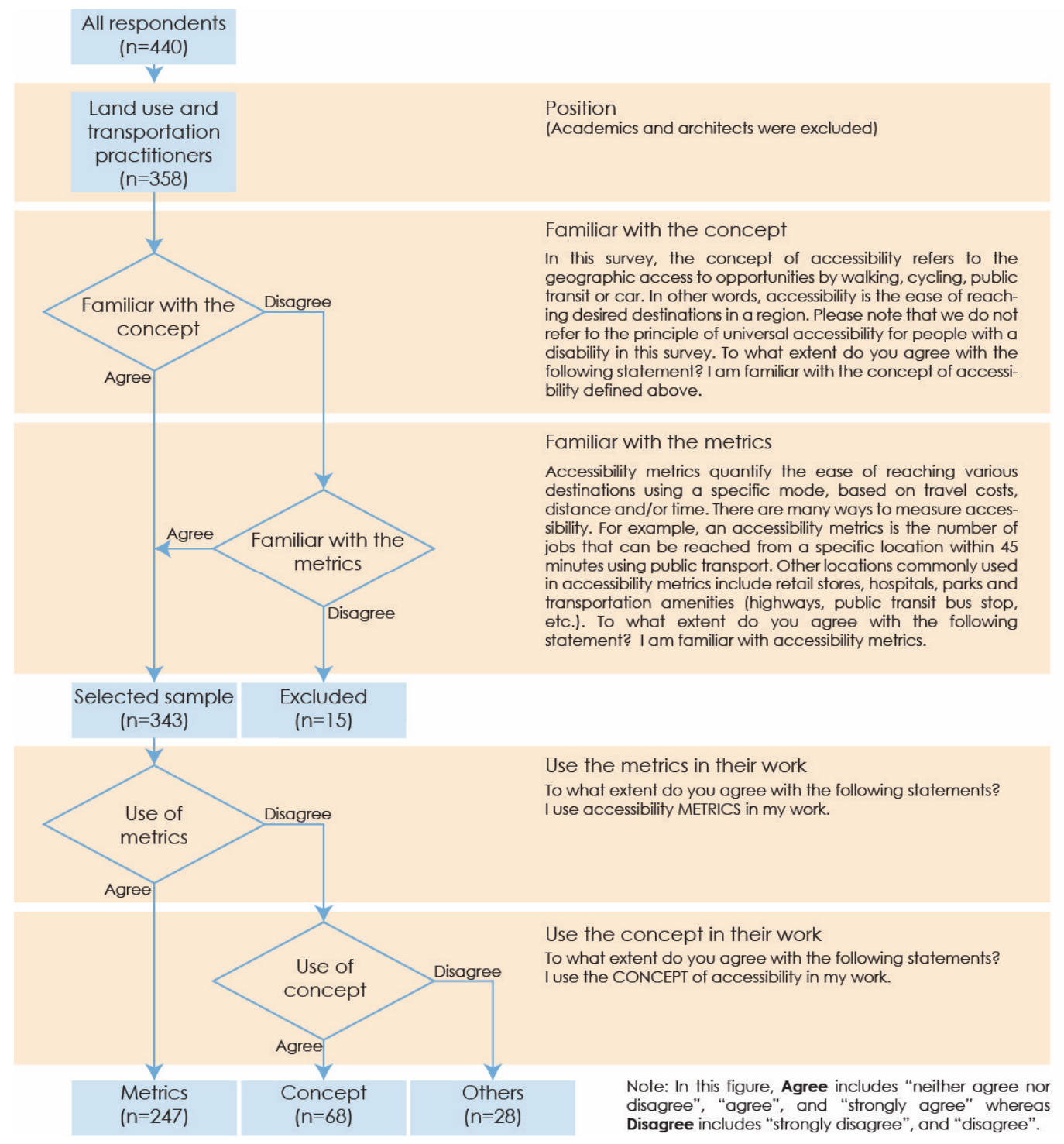

\section{FIGURE 1 Description of the Sample}

The characteristics of the 343 respondents included in our sample are presented in FIGURE

2. Most respondents worked in the public sector (73\%), and the majority were planners (62\%). Respondents were mainly working within a governmental organization, a planning organization, or a consulting agency, while very few worked for a public transport providers. Furthermore, the majority of respondents were involved with transportation projects (public transit, walking, cycling, driving, parking or land use) at the local or regional scale.

Since the sampling method used is this survey is non-probabilistic, the sample is not representative of all land use and transportation practitioners. The results represents the views of 
the 343 respondents included in the survey, and are useful to explore the perceptions of a variety of practitioners. Although the results cannot be generalized to the whole community of practitioners, the findings uncover clear and homogenous trends that could be further investigated.

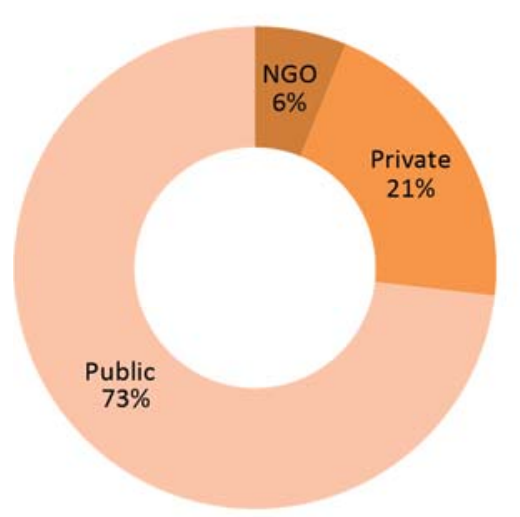

Sector of Employment

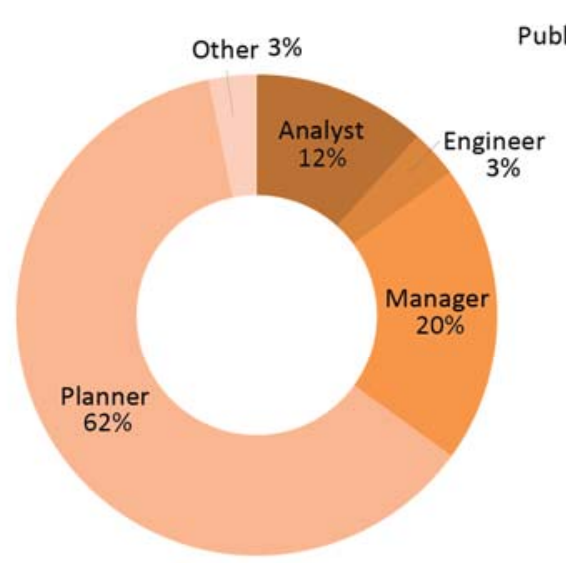

Position

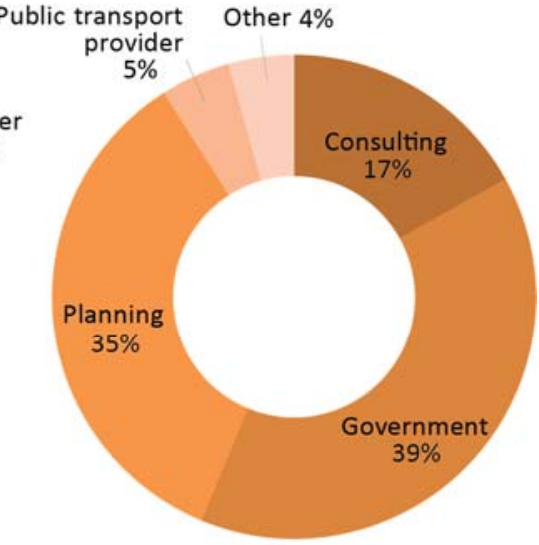

Organization

\section{FIGURE 2 Profile of the Respondents, by Sector of Employment, Position, and Organization}

There are some limitations to this study. Firstly, the sample is largely composed of practitioners from North America, and to a lesser extent, Europe. Further research could include a greater number of respondents from a variety of countries. Doing so would allow comparative analyses between different countries and regions and could help investigate the influence of national and regional context on practitioners. Secondly, this research focuses on location-based accessibility metrics, as they are most commonly used in planning and well suited to provide a regional evaluation of land use and transportation systems. Furthermore, compared to personbased and utility-based metrics, these measures are easy to operationalize and communicate (van Wee and Geurs, 2016), which supports their wide use in research and planning. Yet, further studies could look into the use of person-based and utility-based accessibility metrics. Thirdly, this study is mainly concerned with the geographic access to destinations and does not address the financial, cultural, and cognitive factors that can prevent someone from accessing opportunities. Furthermore, it does not account for communication technologies, or on-site services, that can 
provide access without the need to physically reach a destination. Nevertheless, geographic access is a key component of accessibility in the broad sense, and has been shown to positively contribute to quality of life, employment and modal shift.

\section{RESULTS}

From Knowledge to Use of Metrics

All respondents were asked about whether they were familiar with the accessibility concept and metrics, and whether they used them in their work, based on the definitions of the concept and metrics provided in the survey (see FIGURE 1). The patterns are similar across sectors of employment, positions, and organizations, and thus presented in an aggregated manner in FIGURE 3. FIGURE 3 illustrates the proportion of respondents that agreed with each of the statements. In all cases, more than $50 \%$ of the respondents agreed with the statement, suggesting that the majority of respondents are familiar with the concept and metrics, and use them in their work. This high penetration rate is partially explained by the non-random selection of participants. In fact, there was an effort to disseminate the survey to practitioners who do work with accessibility, as the aim was to understand how accessibility is designed and used in practice. Furthermore, practitioners with a prior knowledge of accessibility were more likely to fill out the survey.

Nevertheless, the comparative assessment of the familiarity and use of the concept and metrics sheds light on current practices. Interestingly, $90 \%$ of the respondents are familiar with the concept of accessibility and $86 \%$ of the respondents use the concept of accessibility in their work. This indicates that almost all the respondents that are familiar with the concept use it in their work. Not surprisingly, a slightly lower proportion of respondents (78\%) are familiar with the metrics. Yet, only 55\% of these respondents use them in their work. There is an important discrepancy between the number of respondents that are familiar with the metrics and the ones who use it. These findings suggest that although practitioners are familiar with the metrics, some factors prevent them from using them in their workplace. These factors are further explored in the next section. 


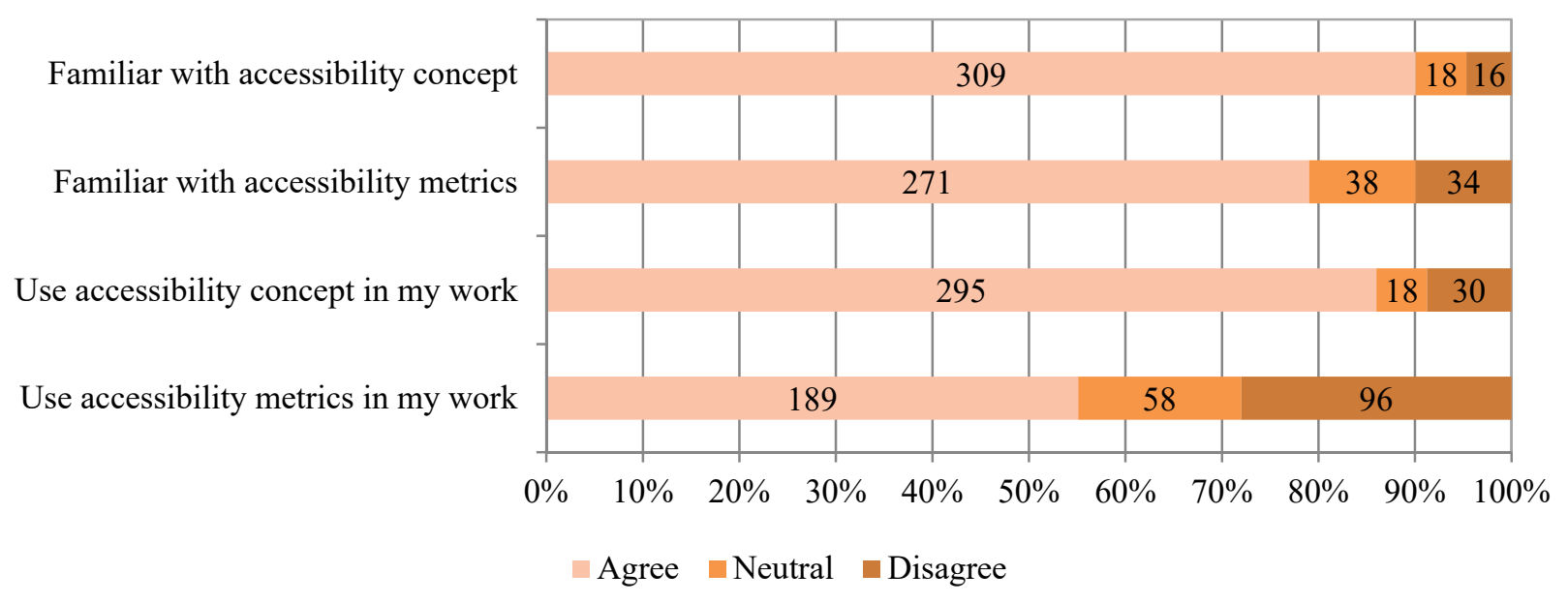

\section{FIGURE 3 Familiarity with and Use of Accessibility (Concept and Metrics)}

Motivations and Barriers

To better understand the factors underlying the use of the accessibility concept and metrics, respondents were asked about the reasons for which they generated accessibility metrics. For those who did not use accessibility metrics in their work, we asked them about the barriers preventing it. For both questions, respondents had to select all options that applied from a predefined list of factors (see FIGURE 4 for the exhaustive list of factors). Respondents also had the possibility to select "other" and to write a different reason. Error! Reference source not found. shows the motivation for using accessibility metrics (among respondents who use the metrics) and the barriers to using them (among respondents who used the concept, but not the metrics).

Only $22 \%$ of the respondents that used accessibility metrics in their work stated that the metrics were present as a tool prior to their arrival. Similarly, few respondents $(16 \%)$ stated that it was a request from their superior. These results suggest that, although most practitioners are familiar with the concept and metrics, accessibility is not widely implemented as a planning tool in our sample. In contrast, the main motivation for using the metrics comes from the respondent's initiative: $36 \%$ of the respondents stated that the generation of accessibility metrics was their own initiative. This indicates that promoting accessibility among practitioners can be an efficient way to foster the use of accessibility metrics as a planning tool. Furthermore, $30 \%$ of the respondents indicated that the generation of metrics resulted from a requirement from a planning document. Accordingly, integrating accessibility indicators in planning documents can help practitioners in integrating accessibility metrics in their work. Finally, a request from a client is the least important 
motivation. This could be due to the low representativeness of respondents from the private sector in our sample.

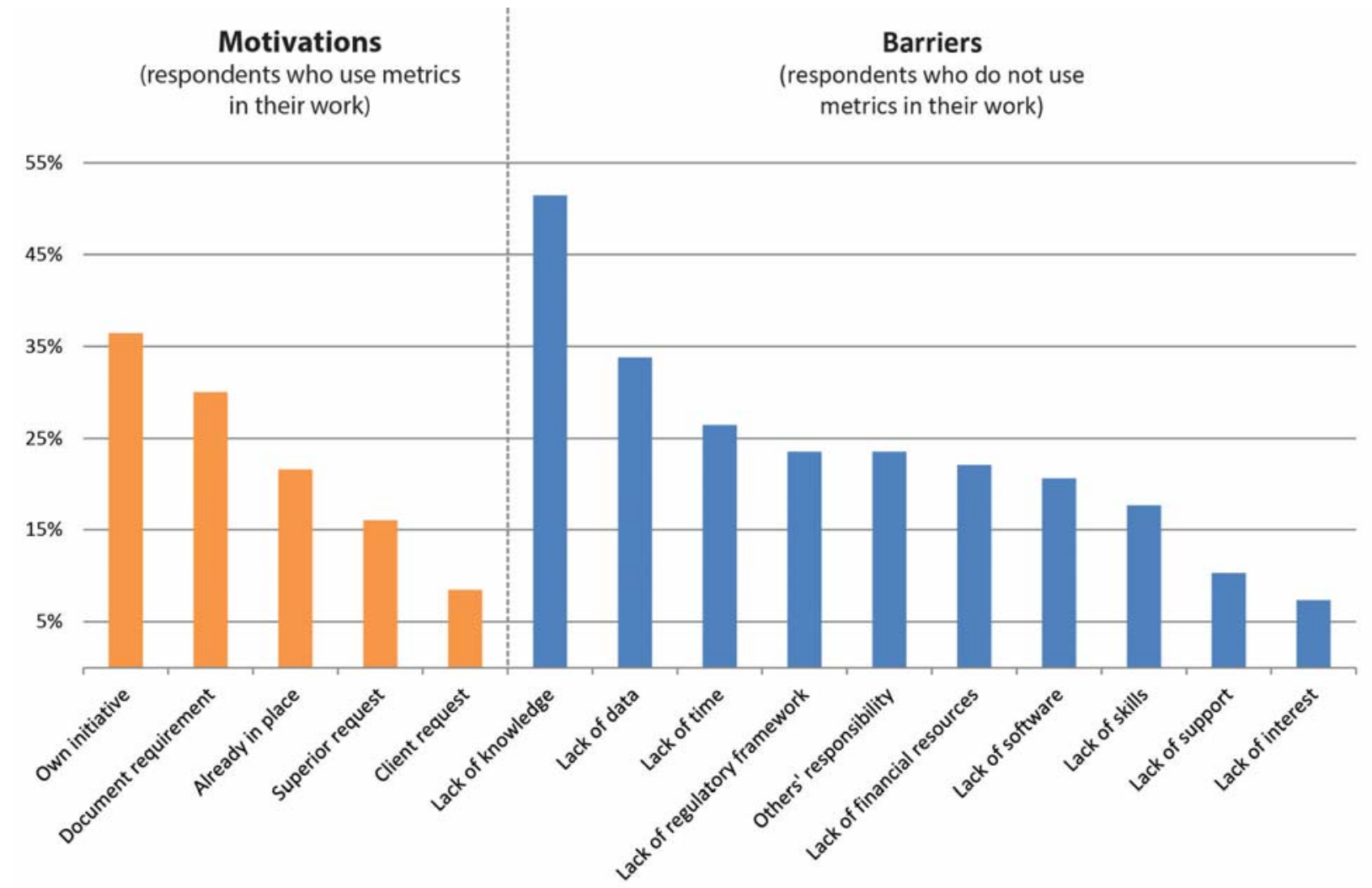

\section{FIGURE 4 Motivations and Barriers to the Use of Accessibility Metrics}

Error! Reference source not found. FIGURE 5 presents the motivations for using accessibility metrics, by sector of employment. Not surprisingly, the proportion of respondents who stated that the generation of accessibility metrics was their own initiative is greater for respondents from the private sector, whereas a requirement from a planning document is most frequently cited by respondents from the public sector. The generation of accessibility metrics due to a requirement from a planning document is in fact the most commonly cited reason in the public sector ( $47 \%$ of the respondents), highlighting the potential influence of planning documents on practitioners from the public sector. With respect to the private sector, a request from a client is the second most commonly cited motivation (33\% of the respondents). As transportation planning clients are often public entities such as municipalities or regional governments, planning documents can also play an important role here. Indeed, having clear accessibility requirements can support the integration of accessibility metrics in outsourcing contracts. 


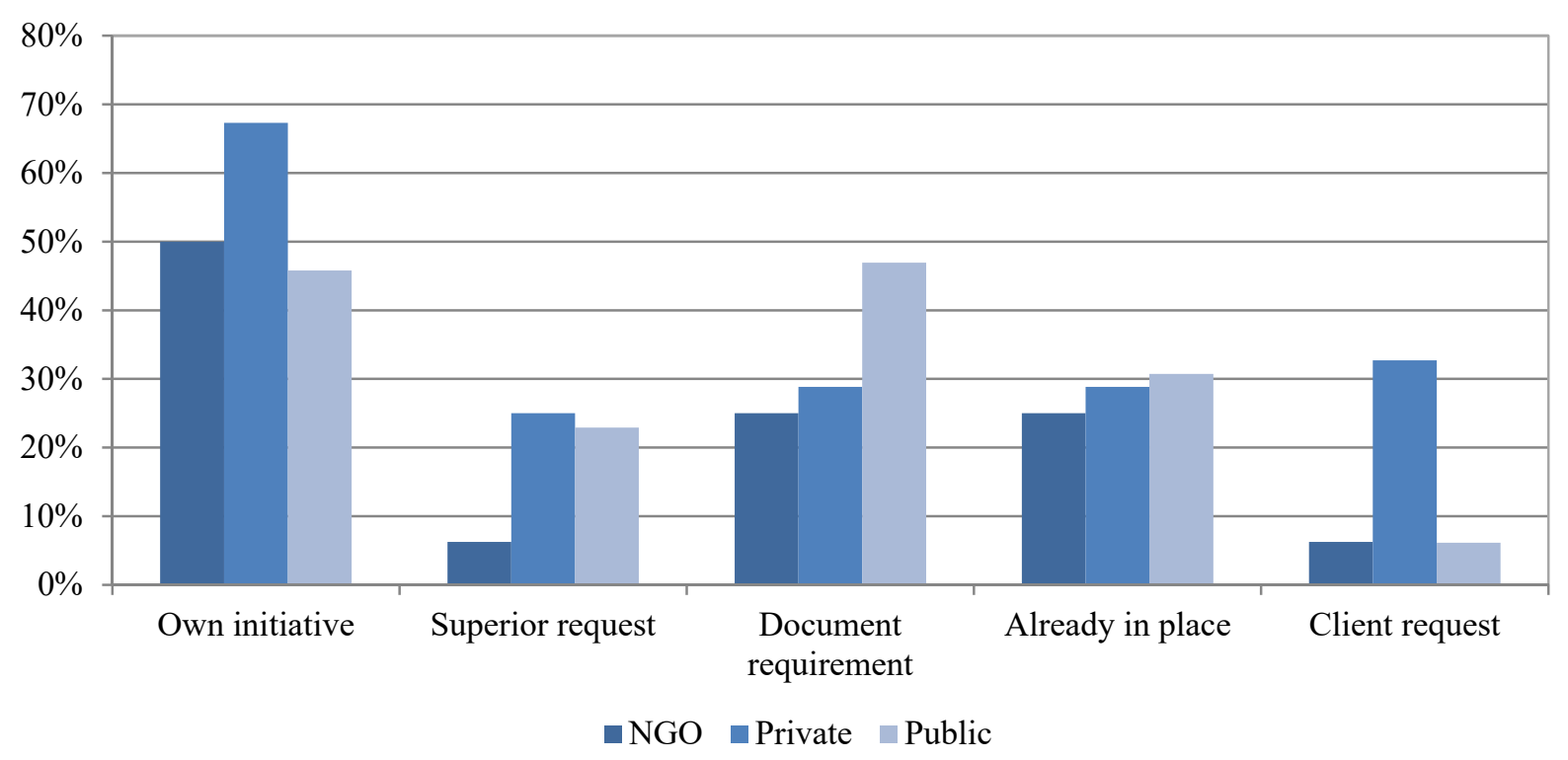

FIGURE 5 Motivations to the Use of Accessibility Metrics, by Sector of Employment

With respect to the respondents who did not use accessibility metrics in their work (FIGURE 4, right), the barrier most frequently is the lack of knowledge (52\%). These findings highlight the need to train future and current practitioners on accessibility metrics, especially since the survey revealed that most metrics were generated as a result of the respondents' own initiative. Furthermore, another important barrier is the lack of data to generate accessibility metrics (34\%). Yet, many accessibility metrics can be generated through open-source data, for example using General Transit Feed Specification data, and open Geographic Information System (GIS) such as QGIS. With respect to the location of jobs or other opportunities, these can be obtained from various sources. Accordingly, the lack of data could also be addressed by training practitioners on how to collect adequate data to generate accessibility metrics, and on the different data sources and tools that are available in different regions. Finally, it is also interesting to note that the lack of interest (7\%) and lack of support (10\%) are the least commonly stated barriers to using accessibility metrics. Practitioners hence do not appear to be reluctant to implementing accessibility-based approaches. Rather, knowledge factors prevent them from generating accessibility metrics.

A previous study on the use of accessibility instruments by practitioners in Europe found that the lack of resources, including time, money, data and computational skills in the participants' organization were perceived as important barriers by the participants (te Brömmellstroet et al., 2014). Furthermore, the lack of funding and resources has been identified as a major barrier to the 
implementation of accessibility planning in the UK (Lucas, 2006; Geurs and Halden, 2015). In our study, many respondents (between 16\% and 34\%) also identified the lack of resources (either data, time, money, software or skills) as a barrier. Although the lack of knowledge is most commonly cited, our findings confirm the presence of institutional barriers to the adoption of accessibility metrics by practitioners. While the studies discussed above are based on European practices, our sample is largely represented by practitioners outside of Europe and thus suggests that these barriers are not unique to the European context.

Other cultural, political and institutional factors have also been found to limit the use of accessibility metrics in practice in Europe. Namely, researchers discussed the lack of integration and collaboration between urban and transportation planning departments and practitioners as well the culture in the transport profession (Papa et al., 2014; Geurs and Halden, 2015). In this regard, further context-specific research is needed to explore the institutional, cultural and political barriers to the adoption of accessibility metrics in practice, especially in North America. Nonetheless, our study suggests that targeting practitioners can contribute to fostering the use of accessibility metrics by removing a major knowledge barrier that has been identified in this study.

Taken together, the findings suggest that practitioners are open to using accessibility as a tool, but that the lack of knowledge prevents some of them from doing so. Accordingly, more effort is needed to train current and future practitioners about the generation of accessibility metrics. In fact, previous research has shown that an improved dialogue between researchers, practitioners, and software and tool developers can better support the use of planning tools, and more specifically accessibility planning tools, in practice (te Brömmelstroet, 2010; te Brömmellstroet et al., 2014; te Brömmelstroet et al., 2016). Namely, in a series of workshop on accessibility instruments in Europe, researchers reported a disconnect between practitioners' needs and the tools developed by researchers and developers (te Brömmelstroet, 2010; te Brömmelstroet et al., 2016). Accordingly, in addition to a traditional transfer of knowledge from researchers to practitioners, collaborative workshops can effectively contribute to a greater use of metrics in practice. This is, once again, especially relevant in the North American context, given that a large proportion of our respondents are from the United States and Canada. 
With respect to planning documents, respondents were asked about the presence of accessibility in the planning documents that they work with. The following questions were asked: To what extent do you agree with the following statements?

- The concept of accessibility is included in the planning documents of the region I work in.

- Accessibility is stated as a main goal in the planning documents of the region I work in.

- Clearly defined accessibility indicators are included in the planning documents of the region I work in.

Around $74 \%$ of the respondents stated that the concept of accessibility is included in the planning documents of their region, whereas 59\% indicated that accessibility was stated as a goal (FIGURE 6). Furthermore, only $38 \%$ of them agreed that clearly defined accessibility indicators were present in the planning documents. These findings are in line with previous studies that found that although accessibility is included in most planning documents, few of them have clear accessibility goals and indicators that guide the decision-making processes (Handy, 2005; Proffitt et al., 2015; Boisjoly and El-Geneidy, 2017).

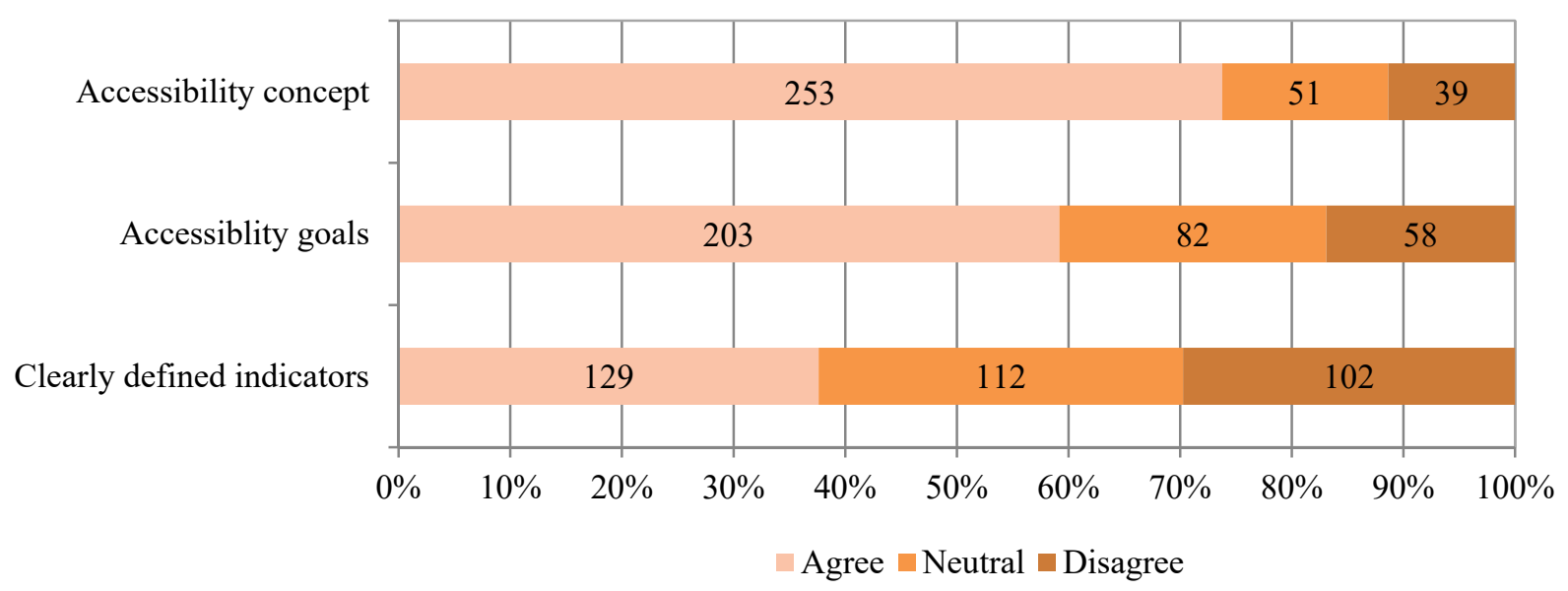

\section{FIGURE 6 Presence of Accessibility in Planning Documents}

The presence of accessibility in planning document is further explored by comparing the results between respondents that used accessibility metrics, respondents that used the concept but not metrics, and respondents that did not use accessibility in their work. Note that, for the purpose of this analysis, respondents who selected "neither agree nor disagree" with respect to the use of the concept or metrics were not considered as respondents that did use the concept or metrics, respectively. FIGURE 7 illustrates the proportion of respondents that agreed with each statement, 
for each group. Respondents that do not use accessibility in their work agreed in the lowest proportion that the concept of accessibility is included in the planning documents they work with, and that accessibility is stated as a goal. These results suggest that the presence of accessibility, and its statement as a goal, are associated with a greater use of accessibility (both in terms of the concept and metrics). Note that a statistical difference test (Tukey HSD) was performed to compare the average Likert scale values (from 1 to 5) between groups. Statistical differences (at the $90 \%$ confidence level) were observed between respondents that do not use accessibility, and the ones that do (metrics or concept), further supporting the results discussed above.

With respect to indicators, the proportion of respondents that agreed that clear accessibility indicators were included in the planning documents is much higher among respondents who used accessibility metrics in their work. In this case, statistical differences in the average Likert scale values were found between respondents that used metrics and the two other groups. These results suggest that the presence of clear accessibility indicators in planning documents foster the use of accessibility metrics by practitioners. Whereas goals are associated with respondents that use accessibility in general, clear indicators are more strongly linked to the use of metrics. This is once again not a surprising result, but highlights the strong importance of having clearly defined indicators in planning documents.

These findings confirm that planning documents can play a key role in motivating practitioners to use accessibility metrics in their work. Furthermore, it emphasizes the need to include clearly defined indicators of accessibility in planning documents, in addition to the overarching goals. In this regard, Boisjoly and El-Geneidy (2017) found that the use of broad accessibility goals in metropolitan plans is often not translated in performance indicators that reflect the ease of reaching destinations, especially when the accessibility goals are not clearly defined. In sum, this study reiterates the importance of defining clear goals and indicators in metropolitan land use and transportation plans in order to support the use of accessibility metrics. 


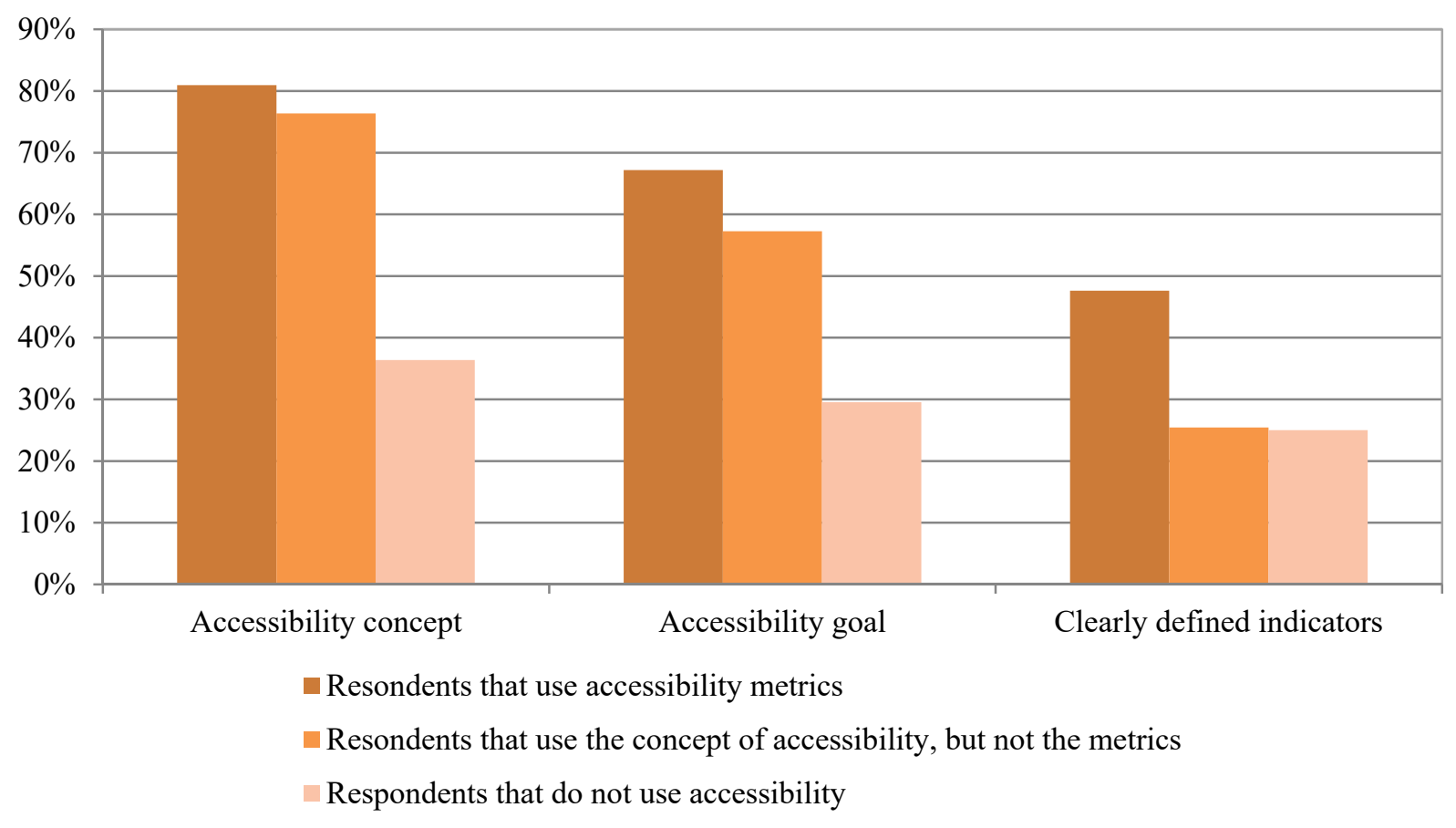

FIGURE 7 Presence of Accessibility in Planning Documents, by Use of Accessibility The Use of Accessibility Metrics

\section{Modes and destinations}

In terms of accessibility indicators, the survey investigated which modes and destinations were considered by practitioners. As we can see in FIGURE 8 and FIGURE 9, public transit is dominant, both in terms of modes assessed and types of destinations (access to public transportation stops). Access to public transit is a measure of service coverage that is widely used by public transit providers and in metropolitan transportation plans (Metrolinx, 2008; LTA, 2013; CMAP, 2014). It is a simple and effective measure that reflects the spatial expansion of the network. Yet, such measure only captures one component of accessibility, as it does not include the location of opportunities. For example, an individual can have good access to a public transit stop, but the bus line serving this stop might not lead to a high number of opportunities. To effectively capture the ease of reaching opportunities, access to destinations must be considered. In this regard, access to jobs and employment clusters, although not as commonly used as access to public transit, is used by a vast majority of respondents ( $72 \%$ and $60 \%$ respectively), while access to other types of destinations (green amenities, retail stores, healthcare services, and cultural and leisure activities) is used in a lower proportion (between $40 \%$ and $50 \%$ ). Access to jobs is also most commonly used 
in accessibility research, namely to explore unemployment rates and commuting mode choice (Korsu and Wenglenski, 2010; Owen and Levinson, 2015b). While access to other types of destinations also plays a key role in achieving social, economic and environmental goals, accessto-jobs metrics provides a regional assessment of the land use and transportation systems, and is accordingly used in multiple studies and metropolitan transportation plans (Bocarejo and Oviedo, 2012; Manaugh and El-Geneidy, 2012; Owen and Levinson, 2015a; Boisjoly and El-Geneidy, 2017). Indeed, since most activities and amenities are associated with the presence of jobs, access to jobs reflects, to a large extent, the quality of the transportation network in relation to the location of opportunities in a region. Since our sample is mainly composed of planners $(62 \%)$, the relevance of job accessibility metrics for regional planning assessment likely explains the large proportion of respondents using jobs or employment clusters as destinations. The wide use of job accessibility metrics in research also contributes to its adoption by practitioners.

In terms of modes, access by public transit is used by the greatest number of respondents. A variety of factors might contribute to this result. Firstly, since the availability of GTFS data, accessibility by transit has become a major trend of accessibility research (Lei and Church, 2010; Owen and Levinson, 2015b). It is also widely incorporated in accessibility instruments, more than car travel according to a recent study on accessibility instruments in Europe (Hull et al., 2012). The wide dissemination of public transit accessibility metrics in research and by developers likely contributes to the use of such metrics by practitioners. Also, from a sustainability and equity perspective, improving accessibility by transit is increasingly considered as desirable (Golub and Martens, 2014; Owen and Levinson, 2015b).

Whereas cycling and walking accessibility is not as commonly assessed by practitioners, researchers recently emphasized the need for accessibility research focusing on active transportation modes (Hull et al., 2012; van Wee and Geurs, 2016). While there is a large body of literature on accessibility by car and public transit, few studies have assessed accessibility by walking or cycling. Although there seems to be emerging research on this topic (Iacono et al., 2010; Owen et al., 2015), the gap in research likely explains the low penetration of active mode accessibility indicators. 


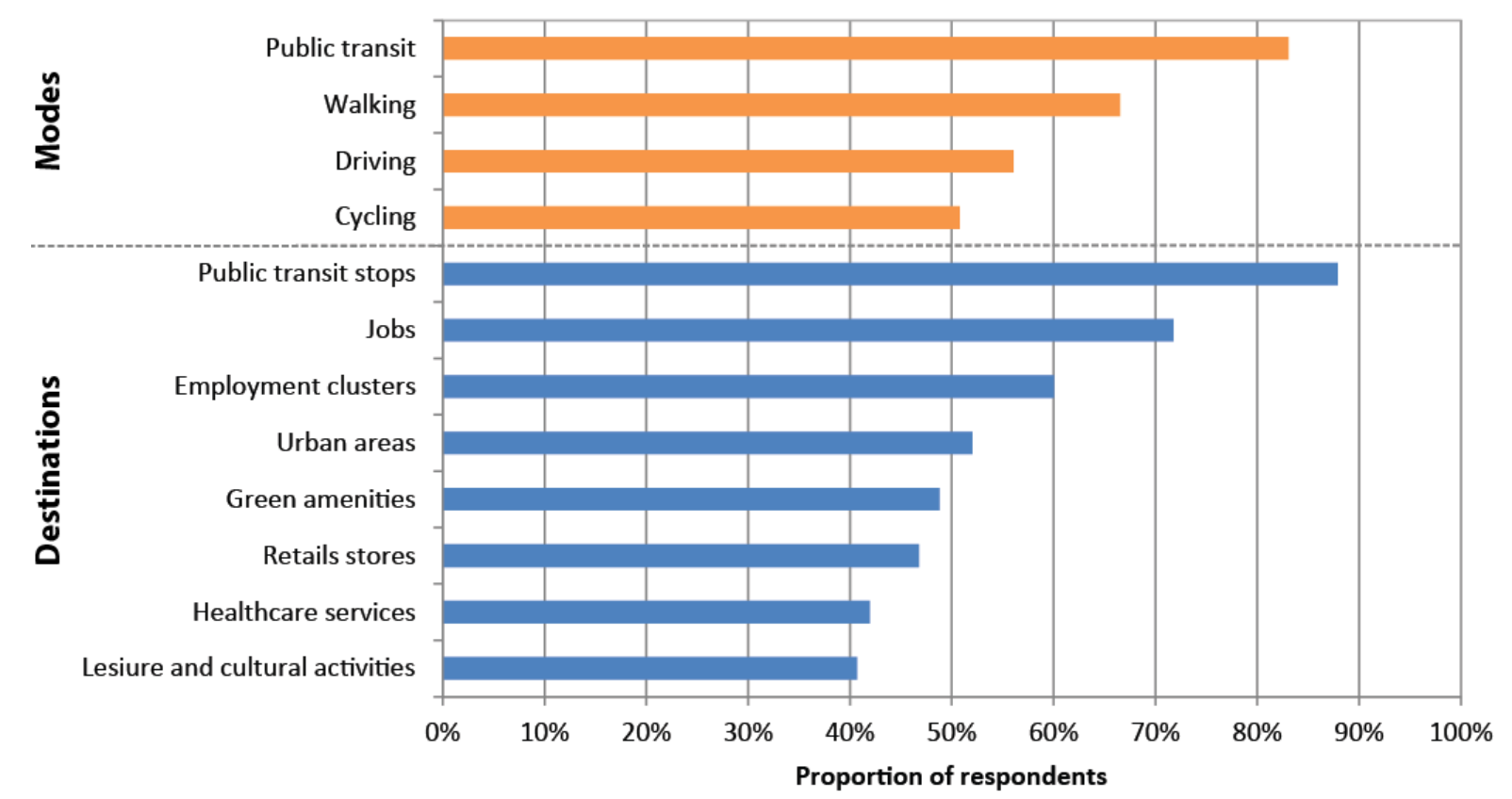

FIGURE 8 Accessibility Metrics - Modes and Destinations

Types of Metrics

Respondents were also asked to select the types of metrics that they used in their work. As we can see in FIGURE 9, the most commonly used metrics are travel time proxies. In line with these findings, a recent study found that travel time proxies are also widely used in metropolitan transportation plans across the United States (Proffitt et al., 2015). Density and land use mix proxies are also commonly used by the respondents, as shown in FIGURE 9. However, travel time, density and land use proxies do not fully reflect the ease of reaching destinations, as they do not address the interactions between the land use and transporation systems.

In this regard, a large proportion of respondents use location-based metrics (cumulativeopportunity and gravity-based metrics), which reflect the ease of reaching destinations and account for both the land use and transport components. Cumulative-opportunity metrics are used in greater proportion by the respodnents, as can be seen in FIGURE 9. While gravity-based metrics more closely reflect travelers' perceptions of time (Ben-Akiva and Lerman, 1979), they are more difficult to generate and to communicate. In contrast, cumulative-opportunity measures are easier to generate and to interpret (Geurs and van Wee, 2004), and thus most commonly used in planning. Cumulative-opportunity metrics are highly correlated with gravity-based metrics, and thus represent appropriate measures of regional accessibility (El-Geneidy and Levinson, 2006; Boisjoly 
and El-Geneidy, 2016). The results indicate that accessibility metrics used by practitioners are generally based on travel time or distance. These thresholds are also largely used in accessibility research, while a few studies have incorporated generalized costs (Currie, 2004; Bocarejo and Oviedo, 2012; El-Geneidy et al., 2016). Although generalized costs better represent the time and monetary values associated with a trip, metrics based on time generally adequately reflect accessibility, as they are highly correlated with mode choice (Anderson et al., 2012; Legrain et al., 2015).

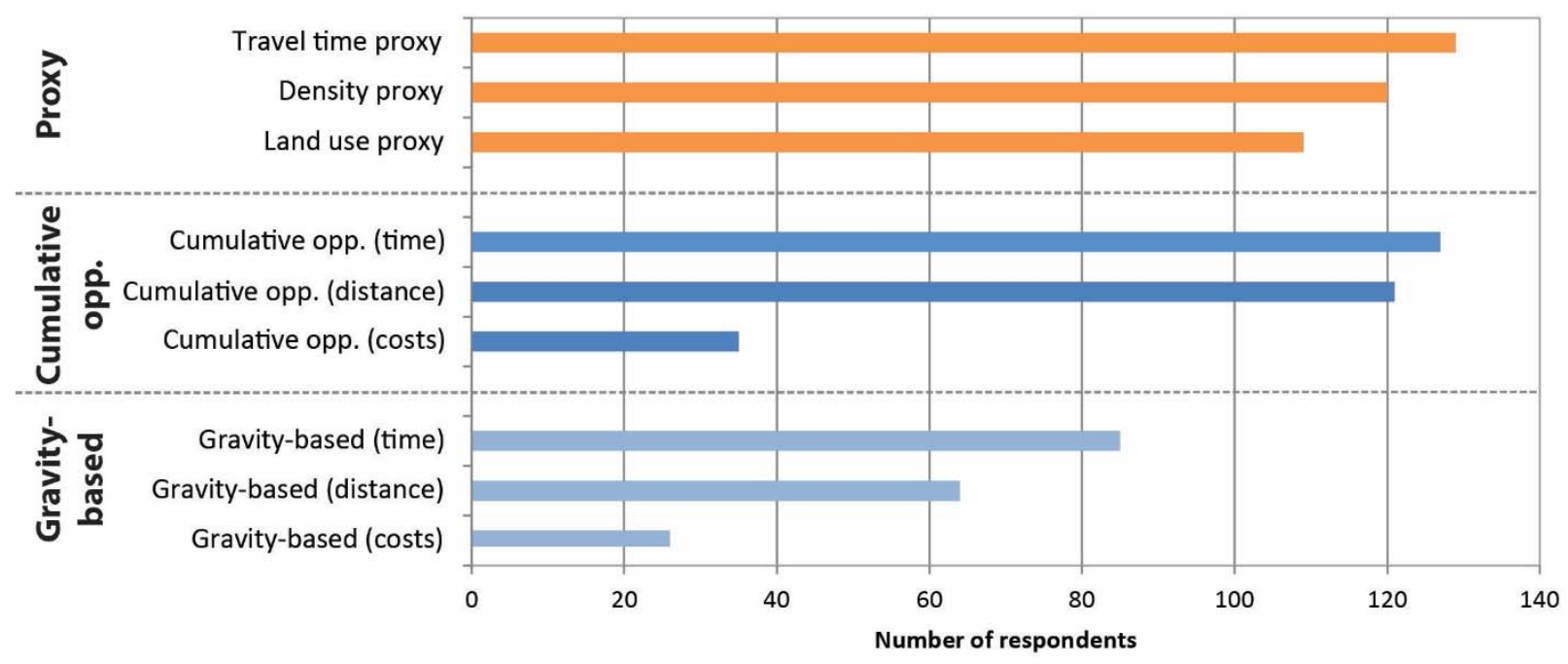

\section{FIGURE 9 Types of Accessibility Metrics Used by Practitioners}

In sum, among the 189 practitioners who agreed ("agree" or "strongly agree") that they use accessibility metrics in their work, $22 \%$ (42 respondents) of them did not use indicators that reflect access to destinations. 40 respondents merely used proxies (travel time, density, land use mix) and 2 respondents only used access to transit metrics. Overall, $43 \%$ of all respondents $(n=343)$ use metrics reflecting access to destinations, while 55\% stated that they use accessibility metrics in their work (FIGURE 3).

The wide use of proxies is likely associated with their ease of generation, interpretation and communication. However, proxies do not fully capture the interactions between land use and transportation systems as they do not jointly account for the characteristics of the land use and transportation sytems. In fact, greater mobility, reflected in reduced travel times, does not necessarily equate with greater accessibility (Ferreira and Batey, 2007). While reduced travel times can reflect greater accessibility in the short run, they can also result in greater travel distances and costs in the long run (Levine et al., 2012). If reductions in travel times are due to road expansions 
and increased travel speeds, the interventions are likely to yield a greater dispersion of destinations, as a result of induced demand and land use development (Handy, 2002; Levinson and Krizek, 2007). Such mobility-oriented development typically leads to greater travel costs, increased driving, and greater discrepancies in accessibility. Accordingly, independent mobility goals might not fully address the broader societal goal of transportation of providing acces to destinations within reasonable time and costs (Handy, 2002; Banister, 2008; Levine et al., 2012). While the focus on mobility has favoured urban sprawl in the last decades, a focus on accessibility is more likely to provide all individuals with more options, and to reduce the need to drive (Handy, 2002; Banister, 2008). As highlighted by Geurs and Halden (2015), potential accessibility indicators, measuring the ease of access to a variety of destinations, need to be included in transportation planning in addition to transport performance indicators such as travel times or costs. With respect to density and land use proxies, increasing density and mix of use has the potential to increase access to destinations, and is thus a relevant metric to address planning for accessibility (Levine et al., 2012). Yet, it does not account for the transport component.

Taken together, these findings reiterate the importance of training current and future practitioners about accessibility metrics and having clearly defined accessibility indicators in planning documents. More specifically, a clear distinction should be made between mobility and accessibility indicators, and access to destinations should be emphasized. Furthermore, a greater collaboration between practitioners, researchers and developers can contribute to bridging the gap between the effectiveness and the usability of metrics.

\section{Accessibility and Decision-Making}

Another important component of accessibility metrics is their potential to influence decisionmaking. In this regard, respondents were asked about the relevance of accessibility metrics to planning and decision-making. Results are presented in FIGURE 10. As in the previous analysis, respondents who selected "neither agree nor disagree" with respect to the use of the concept or metrics were not considered as respondents that did use the concept or metrics, respectively.

As we can see in FIGURE 10, more than 95\% of the respondents who do use accessibility metrics agreed that accessibility metrics can and should influence decision-making, and that accessibility metrics are useful planning tools. The proportion of respondents that agreed that accessibility metrics can and should influence decision-making is lower, however, among 
respondents who do not use accessibility metrics, especially those who do not use the concept nor the metrics. Although not surprising, this finding could suggest that as more practitioners use accessibility metrics, a greater proportion will perceive those metrics as a potential planning tool to inform decision-making. It could also reflect that practitioners who perceive accessibility as useful for decision-making are more inclined to using accessibility metrics.

For all three statements, statistical differences were observed in the average Likert scale values between respondents that use accessibility metrics and the two other groups, whereas the difference between the respondents that use the concept (not the metrics), and respondents that do not use accessibility were not statistically different.

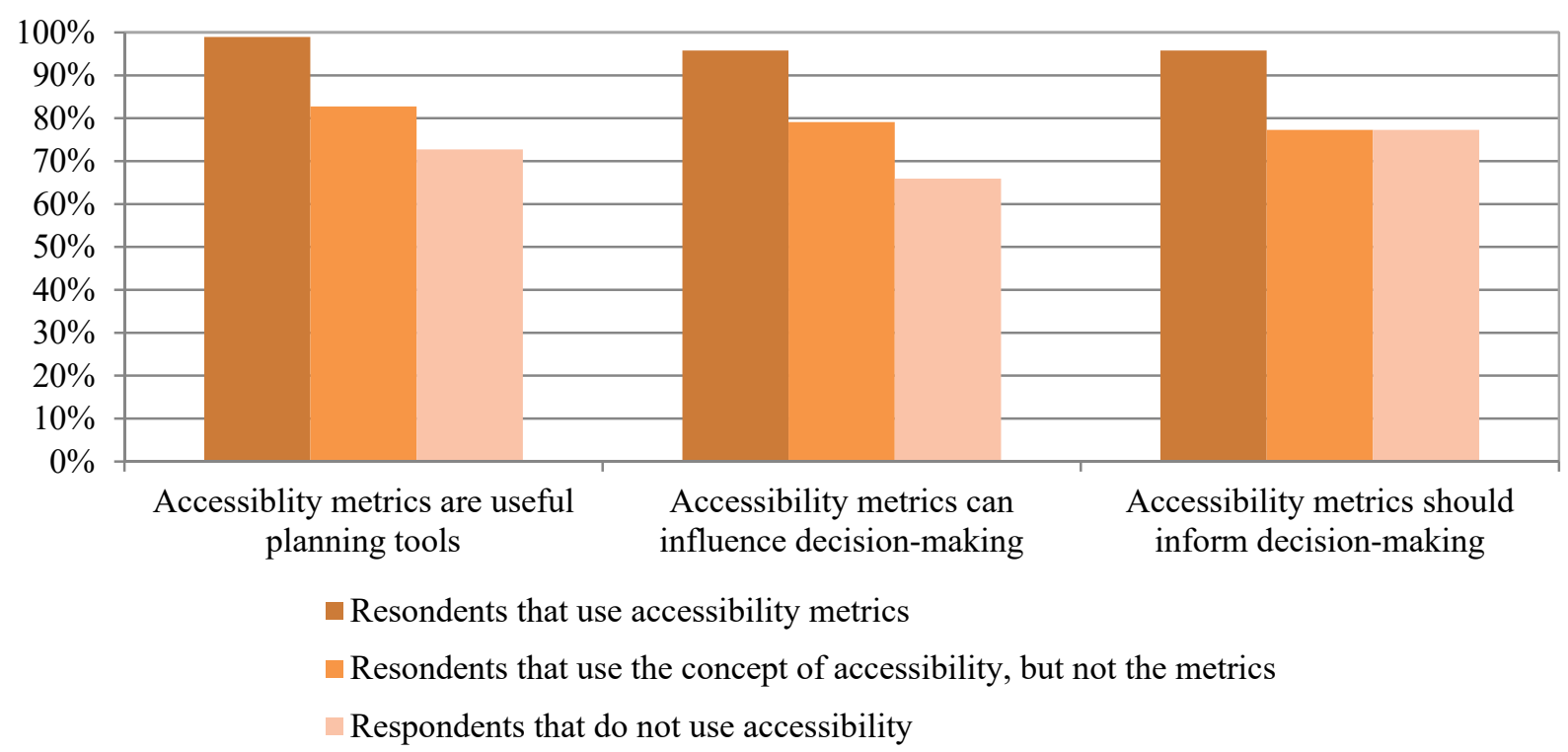

FIGURE 10 Relevance of Accessibility Metrics to Planning and Decision-Making

Respondents who did use accessibility in their work were also asked for what purpose they used the concept or the metrics of accessibility. Interestingly, in both cases, the main purpose was for decision-making (59\% for the concept and 47\% for the metrics). These findings are coherent with the results discussed above. Clearly, there is an agreement among most practitioners that accessibility is an important component of decision-making.

\section{CONCLUSION}

This study investigated the design and use of location-based accessibility metrics by land use and transportation practitioners. It has shown that there is an important gap between the knowledge of 
the concept of accessibility, and the use of accessibility metrics by practitioners. While most practitioners surveyed are familiar with the concept of accessibility, a much lower proportion of respondents (55\%) stated that they use accessibility metrics in their work and only $43 \%$ of the respondents used accessibility metrics that actually reflect the ease of reaching destinations. In contrast, access to public transit and travel time proxies were most commonly used by practitioners.

Whereas lack of support and interest does not appear to be a major obstacle to generating accessibility metrics, lack of knowledge and data are highlighted as the main barriers. In contrast, the use of metrics is largely due to the planners' own initiative. These findings suggest that working directly with practitioners can effectively foster the use of accessibility metrics in practice. More specifically, such efforts can contribute to the use of metrics in practice by: i) providing practitioners with a greater understanding of the various types of metrics, ii) improving their knowledge on how to generate such metrics, and iii) highlighting the value of using these metrics for land use and transportation planning. Furthermore, greater collaboration between researchers and practitioners as well as developers can help aligning research and development with the practical challenges and needs. Given that accessibility is now a mature field of research, there is a potential to strengthen the links between the different actors and to increase collaborations between academics and practitioners. In the European context, the Cost Action on accessibility instruments, bringing together developers, researchers and academics, found positive results suggesting that workshops can contribute to promoting the use of accessibility instruments in practice. Namely, they reported that participants were satisfied with the workshops and intended to use the insights gained from the workshop in their work, and share them within their organizations (te Brömmellstroet et al., 2014). Our study highlights the need for similar projects, especially in North America.

In addition to working closely with practitioners, the presence of clear accessibility indicators is key to promote the use of accessibility metrics by practitioners. Planning document requirements are key motivations stated by practitioners using accessibility metrics. Yet, most respondents, especially the ones that do not use accessibility metrics, indicated that the planning documents of the region they work in do not include clear accessibility indicators. National and regional governments and organizations can play a key role in setting clear accessibility requirements for transportation planning processes and planning documents. For example, in the 
early 2000s, the UK established a framework for accessibility planning to ensure that local transportation planning authorities addressed issues of access to opportunities. As a result, accessibility had to be included in transport plans at the local level. Yet, as discussed in the introduction, the flexibility of the guidelines resulted in a multitude of interpretations that did not necessarily translate into access-to-destinations indicators (Curl et al., 2011; Halden, 2011). Nevertheless, the focus on accessibility has contributed to positive achievements in terms of accessibility (Geurs and Halden, 2015). Similarly, the United States has federal transportation planning requirements, one of which emphasizes the need to improve mobility and accessibility. As a result, most regional transportation plans address accessibility in one way or another. However, accessibility goals are rarely translated into accessibility indicators, and accessibility and mobility are often used interchangeably (Handy, 2005; Proffitt et al., 2015). In sum, national policy documents can influence local transportation planning processes, but in order to ensure that accessibility indicators reflecting the ease of reaching destinations are included, clear guidelines must be provided and a clear distinction between mobility and accessibility must be made.

Overall, this study provides a first insight into general and potential measures that can support practitioners in developing accessibility metrics. Training practitioners and setting clear accessibility performance measures in planning documents can contribute to the use of accessibility metrics in practice, which can foster a shift from a mobility-based approach to an accessibility-based approach. While the use of metrics does not encompass all challenges associated with a shift of paradigm in transportation planning, the presence of performance indicators can significantly contribute to including issues of accessibility in decision-making. Indeed, accessibility goals are increasingly incorporated in transportation plans, but the lack of performance indicators limits their influence on planning. Namely, Handy (2008) found that goals without performance indicators received the least weight in metropolitan transportation plans in the US. Similarly, Manaugh et al. (2015) discuss the importance of measuring policy goals, in this case social equity goals, to ensure that they receive greater attention in decision-making. Lucas (2012) also emphasizes the need to establish metrics guiding the provision of public transport for social inclusion, in order to promote the social inclusion agenda. In all cases, research point towards the fact that performance indicators are essential to support the achievement of goals, be it accessibility, social equity of social inclusion. 
This study specifically sheds light on challenges associated with the use of accessibility metrics into practice to contribute to a greater consideration of accessibility issues in decisionmaking. This research also illustrates the need to bridge the gap between accessibility research and practice. The findings are of relevance to planners and policy makers wishing to support accessibility-oriented planning practices and are helpful for researchers to better understand the challenges experienced by practitioners.

\section{REFERENCES}

Anderson, P., Owen, A., Levinson, D., 2012. The time between: Continuously-defined accessibility functions for schedule-based transportation systems. 92nd Annual Meeting of the Transportation Research Board.

Banister, D., 2008. The sustainable mobility paradigm. Transport policy 15 (2), 73-80.

Ben-Akiva, M., Lerman, S., 1979. Disaggregate travel and mobility choice models and measures of accessibility, In: Hensher, D., Stopher, P. (Eds.), Behavioural travel modelling. Croom-Helm, London, pp. 654-679.

Blumenberg, E., Ong, P., 2001. Cars, buses, and jobs-welfare participants and employment access in Los Angeles. Transportation Research Record (1756), 22-31.

Bocarejo, J., Oviedo, D., 2012. Transport accessibility and social inequities: A tool for identification of mobility needs and evaluation of transport investments. Journal of Transport Geography 24, 142-154. Boisjoly, G., El-Geneidy, A., 2016. Daily fluctuations in transit and job availability: A comparative assessment of time-sensitive accessibility measures. Journal of Transport Geography 52, 73-81. Boisjoly, G., El-Geneidy, A., 2017. How to get there? A critical assessment of accessibility objectives and indicators in metropolitan transportation plans. Transport Policy.

Chen, C., Gong, H., Paaswell, R., 2008. Role of the built environment on mode choice decisions:

Additional evidence on the impact of density. Transportation 35 (3), 285-299.

CMAP (Chicago Metropolitan Agency for Planning), 2014. Go To 2040 Plan Update Summary. Chicago, IL: CMAP. Available online at:

http://www.cmap.illinois.gov/documents/10180/332742/Update+Plan+Summary+FINAL+Word.pdf/55c 7e22b-3edb-43cb-a5da-37302d33b17c.

Curl, A., Nelson, J., Anable, J., 2011. Does Accessibility Planning address what matters? A review of current practice and practitioner perspectives. Research in Transportation Business \& Management 2, 3-

11.

Currie, G., 2004. Gap analysis of public transport needs - Measuring spatial distribution of public transport needs and identifying gaps in the quality of public transport provision. Transportation Research Record (1895), 137-146.

Du, H., Mulley, C., 2012. Understanding spatial variations in the impact of accessibility on land value using geographically weighted regression. Journal of Transport and Land Use 5 (2).

El-Geneidy, A., Levinson, D. 2006. Access to destinations: Development of accessibility measures. StPaul, Minnesota, US: Departement of civil engineering, University of Minnesota. Available online at: http://nexus.umn.edu/projects/Access/Access-FinalReport.pdf. 
El-Geneidy, A., Levinson, D., Diab, E., Boisjoly, G., Verbich, D., Loong, C., 2016. The cost of equity: Assessing transit accessibility and social disparity using total travel cost. Transportation research part $A$ 91, 302-316.

Ferreira, A., Batey, P., 2007. Re-thinking accessibility planning: A multi-layer conceptual framework and its policy implications. Town Planning Review 78 (4), 429-458.

Geurs, K., Halden, D., 2015. Accessibility: Theory and practice in the Netherlands and in the UK, In: Hickman, R., Givoni, M., Bonilla, D., Banister, D. (Eds.), Handbook on Transport and Development. Edward Elgar Publishing Limited, Cheltenham, UK.

Geurs, K., Krizek, K., Reggiani, A., 2012. Accessibility analysis and transport planning: An introduction, In: Geurs, K., Krizek, K., Reggiani, A. (Eds.), Accessibility Analysis and Transport Planning: Challenges for Europe and North America. Edward Elgar Publishing Limited, Northampton, pp. 1-12.

Geurs, K., van Wee, B., 2004. Accessibility evaluation of land-use and transport strategies: Review and research directions. Journal of Transport Geography 12 (2), 127-140.

Golub, A., Martens, K., 2014. Using principles of justice to assess the modal equity of regional transportation plans. Journal of Transport Geography 41, 10-20.

Halden, D., 2011. The use and abuse of accessibility measures in UK passenger transport planning. Research in Transportation Business \& Management 2, 12-19.

Handy, S., 1994. Regional versus local accessibility: Implications for non-work travel. Transportation Research Record (1400), 58-66.

Handy, S. 2002. Accessibility- vs. mobility-enhancing strategies for addressing automobile dependence in the U.S., In: Institute of Transportation Studies (Ed.), Recent Work. Davis, US: University of California.

Available online at: http://www.des.ucdavis.edu/faculty/handy/ECMT report.pdf.

Handy, S., 2005. Planning for accessibility: In theory and in practice, In: Levinson, D., Krizek, K. (Eds.), Access to destinations. Elsevier, Oxford, UK, pp. 131-147.

Handy, S., 2008. Regional transportation planning in the US: An examination of changes in technical aspects of the planning process in response to changing goals. Transport Policy 15 (2), 113-126.

Handy, S., Niemeier, D., 1997. Measuring accessibility: An exploration of issues and alternatives.

Environment and Planning A 29, 1175-1194.

Hansen, W., 1959. How accessibility shapes land use. Journal of the American Institute of Planners 25 (2), 73-76.

Huang, R., Wei, Y., 2002. Analyzing neighborhood accessibility via transit in a GIS environment. Geographic Information Sciences 8 (1), 39-47.

Hull, A., Silva, C., Bertolini, L. 2012. Accessibility instruments for planning practice. Porto, Portugal: COST Office. Available online at: http://www.accessibilityplanning.eu/wp-content/uploads/2012/10/COSTReport-1-FINAL.pdf.

lacono, M., Krizek, K., El-Geneidy, A., 2010. Measuring non-motorized accessibility: Issues, alternatives, and execution. Journal of Transport Geography 18 (1), 133-140.

Kawabata, M., Shen, Q., 2007. Commuting inequality between cars and public transit: The case of the San Francisco Bay Area, 1990-2000. Urban Studies 44 (9), 1759-1780.

Koenig, J., 1980. Indicators of urban accessibility: Theory and application. Transportation 9 (2), 145-172. Korsu, E., Wenglenski, S., 2010. Job accessibility, residential segregation, and risk of long-term unemployment in the Paris region. Urban Studies.

Legrain, A., Buliung, R., El-Geneidy, A., 2015. Who, what, when and where: Revisiting the influences of transit mode share. Transportation Research Record (2537), 42-51.

Lei, T., Church, R., 2010. Mapping transit-based access: Integrating GIS, routes and schedules.

International Journal of Geographical Information Science 24 (2), 283-304. 
Levine, J., Grengs, J., Shen, Q., Shen, Q., 2012. Does accessibility require density or speed? A comparison of fast versus close in getting where you want to go in US metropolitan regions. Journal of the American Planning Association 78 (2), 157-172.

Levinson, D., 1998. Accessibility and the journey to work. Journal of Transport Geography 6 (1), 11-21. Levinson, D., Gillen, D., 2005. The machine for access, In: Levinson, D., Krizek, K. (Eds.), Access to Destinations. Elsevier, Oxford,UK.

Levinson, D., Krizek, K., 2007. Planning for place and plexus: Metropolitan land use and transport. Routledge, New York, US.

LTA (Singapore Land Transport Authority), 2013. Land Transport Master Plan 2013. Singapore: LTA. Available online at:

https://www.Ita.gov.sg/content/dam/Itaweb/corp/PublicationsResearch/files/ReportNewsletter/LTMP2 013Report.pdf.

Lucas, K., 2006. Providing transport for social inclusion within a framework for environmental justice in the UK. Transportation Research Part a-Policy and Practice 40 (10), 801-809.

Lucas, K., 2012. Transport and social exclusion: Where are we now? Transport Policy 20, 107-115. Manaugh, K., Badami, M., El-Geneidy, A., 2015. Integrating social equity into urban transportation planning: A critical evaluation of equity objectives and measures in transportation plans in North America. Transport policy 37, 167-176.

Manaugh, K., El-Geneidy, A., 2012. Who benefits from new transportation infrastructure? Using accessibility measures to evaluate social equity in transit provision, In: Geurs, K., Krizek, K., Reggiani, A. (Eds.), Accessibility and Transport Planning: Challenges for Europe and North America. Edward Elgar, London, UK, pp. 211-227.

Metrolinx 2008. The Big Move. Toronto, Canada: Metrolinx. Available online at: http://www.metrolinx.com/thebigmove/Docs/big move/TheBigMove 020109.pdf. Miller, H., 2005. Place-based versus people-based accessibility, In: Levinson, D., Krizek, K. (Eds.), Access to destinations. Elsevier, Oxford, pp. 63-89.

Mondschein, A., Taylor, B., Brumbaugh, S. 2011. Congestion and Accessibility: What's the Relationship?, Earlier Faculty Research. Los Angeles, US: University of California Transportation Center. Available online at: http://escholarship.org/uc/item/6bh2n9wx.

Ornati, O., Whittaker, J., Solomon, R., 1969. Transportation needs of the poor: A case study of New York City. Praeger, New York, US.

Owen, A., Levinson, D. 2015a. Access across America: Transit 2014. St-Paul, Minnesota, US: Center for Transportation Studies, University of Minnesota. Available online at: www.its.umn.edu/Publications/ResearchReports/pdfdownloadl.pl?id=2506 Owen, A., Levinson, D., 2015b. Modeling the commute mode share of transit using continuous accessibility to jobs. Transportation Research Part A: Policy and Practice 74, 110-122.

Owen, A., Levinson, D., Murphy, B. 2015. Access across America: Walking 2014. St-Paul, Minnesota, US: Center for Transportation Studies, University of Minnesota. Available online at: http://access.umn.edu/research/america/walking/2014/documents/CTS15-03.pdf.

Paez, A., Mercado, R., Farber, S., Morency, C., Roorda, M., 2010a. Accessibility to health care facilities in Montreal Island: an application of relative accessibility indicators from the perspective of senior and non-senior residents. International Journal of Health Geographics 9 (52), 1-15.

Paez, A., Mercado, R., Farber, S., Morency, C., Roorda, M., 2010b. Relative accessibility deprivation indicators for urban settings: Definitions and application to food deserts in Montreal. Urban Studies. Paez, A., Scott, D., Morency, C., 2012. Measuring accessibility: Positive and normative implementations of various accessibility indicators. Journal of Transport Geography 25, 141-153.

Papa, E., Silva, C., te Brömmelstroet, M., Hull, A., 2014. Accessibility instruments for planning practice: A review of European experiences. Journal of Tranport and Land Use 9 (3), 1-20. 
Pignatar, L., Falcocch, J., 1969. Transportation needs of low-income families. Traffic Quarterly 23 (4). Preston, J., Rajé, F., 2007. Accessibility, mobility and transport-related social exclusion. Journal of Transport Geography 15, 151-160.

Proffitt, D., Bartholomew, K., Ewing, R., Miller, H., 2015. Accessibility planning in american metropolitan areas: Are we there yet?, Transportation Research Board 94th Annual meeting, Washington, D.C. Sanchez, T., 1999. The connection between public transit and employment: The cases of Portland and Atlanta. Journal of the American Planning Association 65 (3), 284-296.

Sari, F., 2015. Public transit and labor market outcomes: Analysis of the connections in the French agglomeration of Bordeaux. Transportation Research Part A: Policy and Practice 78, 231-251. Straatemeier, T., 2008. How to plan for regional accessibility? Transport Policy 15 (2), 127-137. te Brömmellstroet, M., Silva, C., Bertolini, L. 2014. Accessing usability of accessibility instruments. Amsterdam, Netherlands: COST. Available online at: http://www.accessibilityplanning.eu/wpcontent/uploads/2014/05/COST-REPORT-II.pdf.

te Brömmelstroet, M., 2010. Equip the warrior instead of manning the equipment: Land use and transport planning support in the Netherlands. Journal of transport and land use 3 (1), 25-41. te Brömmelstroet, M., Curtis, C., Larsson, A., Milakis, D., 2016. Strengths and weaknesses of accessibility instruments in planning practice: Technological rules based on experiential workshops. European Planning Studies 24 (6), 1175-1196.

Tyndall, J., 2015. Waiting for the R train: Public transportation and employment. Urban Studies, 0042098015594079.

van Wee, B., 2016. Accessible accessibility research challenges. Journal of Transport Geography 51, 9-16. van Wee, B., Geurs, K., 2016. The role of accessibility in urban and transport planning, In: Bliemer, M., Mulley, C., Moutou, C. (Eds.), Handbook on Transport and Urban Planning in the Developed World. Edward Elgar Publishing, Cheltenham, UK, p. 53.

Vickerman, R., 1974. Accessibility, attraction, and potential: A review of some concepts and their use in determining mobility. Environment and Planning A 6, 675-691.

Wachs, M., Kumagai, T., 1973. Physical accessibility as a social indicator. Socio-Economic Planning Sciences 7 (5), 437-456. 